\title{
UNA HERENCIA SIN TESTAMENTO ${ }^{1}$
}

\section{FranÇOISE COLLIN}

En el presente trabajo Françoise Collin reflexiona sobre el concepto "transmisión" y su papel a la hora de construir una relación simbólica entre distintas generaciones de mujeres. Vinculada a la historia y a la idea de afiliación, constituye además una posibilidad política y ética que puede renovar el feminismo y ayudar a la constitución de un espacio simbólico compartido entre mujeres y hombres.

PALABRAS ClAVE: Françoise Collin, transmisión, feminismo, ética, política.

\section{An Inheritance without a Will}

In the present essay, Françoise Collin reflects on "transmission" as a concept and on its role in the construction of a symbolic relationship between different generations of women. Bound up with history and with the idea of affiliation, "transmission" also constitutes a political and ethical possibility for renewing feminism and aiding in the constitution of a symbolic space shared between women and men.

KEY WORDS: Françoise Collin, affiliation, feminism, transmission, ethics, politics.

¿Qué serán las mujeres del año 2000? A esta interrogación sociológica se le añade una interrogación ética y política: ¿qué querríamos legarles, que querríamos que ellas retuvieran de lo que nosotras hemos entendido y realizado? Es más: ¿qué pueden retener ellas en su propio contexto? ¿Qué pueden comprender de nosotras y de qué forma? Por citar a Hannah Arendt, a quien estas reflexiones deben mucho, "el milagro que salva el mundo, el terreno de los asuntos humanos, de la ruina normal, 'natural', es el hecho de la natalidad, en el cual se enraíza ontológicamente la facultad de actuar. En otras palabras: es el nacimiento de nuevos hombres [de nuevas mujeres], el hecho de que comiencen de nuevo, la acción de la cual ellos [ellas] son capaces por derecho de nacimiento" ( $\mathrm{La}$

\footnotetext{
${ }^{1}$ Aparecido originalmente en Les Cahiers du Grif, 34, "Les jeunes. La Transmission”, invierno 1986. Un artículo accesible en línea retoma esta temática. Véase: Françoise Collin, "Le féminisme pour quoi faire? Genèse et formes d'un mouvement", en: La Revue Nouvelle, noviembre $2004, \mathrm{n}^{\circ} 11$, pp. 9-25: <www.revuenouvelle.be/rvn_abstract.php3?id_article=379> (última consulta el 29-8-2011).
} 
condición humana). Aquí se plantea toda la cuestión de la transmisión. A menudo se ha subrayado, con acierto, que las mujeres no tienen historia: esta afirmación ha significado alternativamente o a la vez que la ciencia histórica las ha borrado de la escena y/o que ellas no han constituido raíz, fatalidad de la que el feminismo no habría logrado liberarlas puesto que este movimiento parece manifestarse únicamente mediante destellos esporádicos.

En la historia general, la historia de los hombres, la sociedad de las mujeres sería una especie de sociedad sin historia, condenada a la repetición de los mismos gestos en torno a lo que se denomina la reproducción, en todos los sentidos del término. Toda tentativa de inauguración se agotaría en sí misma, fracasando en el intento de instaurar lo que podríamos denominar paradójicamente una tradición de lo nuevo. Ahora bien, en la actualidad las mujeres, algunas mujeres, que se han organizado en movimiento, que han luchado individual o colectivamente, que han tomado riesgos y continúan haciéndolo, quisieran y quieren liberar a sus hijas de la reproducción de lo mismo; no se trata de impugnar la maternidad, sino de suscitar en (y al lado de) la reproducción (biológica) la generación (simbólica). Les gustaría que alguna cosa - ¿el qué? - de su trabajo de transformación pasara no solo como una conquista sino como una dinámica por prolongar. Que el ser mujer prosiga su devenir en lugar de regresar a la casilla de salida o de quedar fijado bajo un revestimiento modernizado. Y que las relaciones entre hombres y mujeres sean transformadas. Esta búsqueda, este deseo se concretan en los grupos, las corrientes de ideas, los lugares - casas de mujeres, editoriales, revistas- que no se enorgullecen de lo efímero sino que, al contrario, buscan perdurar renovándose, contra la presión social y económica que prosigue su labor de zapa, y pese a los medios de comunicación y sus prisas por celebrar su muerte. De esta forma las mujeres aprenden a arreglárselas con su propia institucionalización, esto es, a darse un espacio de inscripción que permita asumir el tiempo como continuidad y apertura. No obstante, querer perdurar significa también para cada una aprender a morir, abandonarse a una filiación que da lugar a otra: nombrar y ser nombrada sin la garantía abstracta del linaje patriarcal.

La transmisión no es un movimiento de sentido único. A diferencia de la historia, la transmisión es siempre una operación bilateral, un trabajo de relación que se extrae de lo vivo. No se puede comprender como la transferencia de un objeto de una mano a otra. Exige una doble actividad: por parte de quien transmite y por parte de quien acoge la transmisión. No puede funcionar por obligación. Imbricada en el juego de generaciones, está relacionada con el deseo tanto de las antiguas como de las nuevas. A las nuevas les corresponde determinar si desean la herencia y qué les interesa dentro de esta herencia. A las antiguas les corresponde escuchar la petición, desviar su lenguaje hacia otro lenguaje, en un intercambio en el cual cada una, a la vez que se mantiene en lo que es y hace honor a su propia historia, se dirige a la otra y la escucha. Es 
evidente que no todas nuestras conquistas perdurarán, que ciertos elementos a los que habíamos otorgado un valor considerable caducan o deben retransformarse, y otros, por el contrario, dejan huella, resultan fecundos. Esta selección de la historia que la generación ascendiente ya está realizando es inevitable. Si deseamos que todo lo que hemos conquistado se transmita sin cambio, nos arriesgamos a verlo todo rechazado en bloque. La historia no procede por adiciones sino por reestructuraciones. En nuestra experiencia, en los valores que hemos hecho nuestros, hay algo de inadmisible, al menos como tal. La vida es un inmenso derroche puesto que está inscrita en el tiempo. Lo que una generación retiene de la anterior y lo que hace con este legado es imprevisible y sorprendente. No se puede imponer nuestras voluntades al porvenir: la herencia, según René Char citado por Arendt, no va acompañada de ningún testamento, si por testamento se entiende su modo de empleo:

Nuestra esperanza reside siempre en el elemento de novedad que cada generación aporta con ella; sin embargo, es precisamente porque no podemos colocar nuestra esperanza sino en él que lo destruimos todo si tratamos de canalizar este elemento nuevo para que nosotros, los antiguos, decidamos qué será. [...] La educación debe proteger esta novedad e introducirla como un fermento nuevo en un mundo ya viejo que, por muy revolucionarios que puedan ser sus actos, es, desde el punto de vista de la generación siguiente, anticuado y cercano a la ruina. (Arendt, 2003)

De esta manera nuevos hombres, nuevas mujeres, "recién nacidas", reciben y rompen a la vez: la filiación es el arte de sostener el hilo y de romper el hilo. Lo dado, las cartas repartidas se redistribuyen y se vuelven a jugar. De ahí la vacuidad de una lectura homogénea de los hechos a partir de un instrumento de medida o de un punto de vista establecidos de forma definitiva: la lectura debe leer y releer. $\mathrm{Y}$, en lo que nos concierne, la lectura tiene que permitir desvelar los nuevos retos y las nuevas formas de emergencia de lo que podemos denominar feminismo, en lugar de empeñarse en verlo donde no es más que su propia conmemoración, su monumento. La vigilancia es de rigor. Así pues, no compartiré las lamentaciones sinceras o hipócritas de aquellos y aquellas que van proclamando que el feminismo está acabado, que la gente joven se aparta de él. Tampoco estoy de acuerdo con los medios de comunicación que corean el retorno a los valores tradicionales (como si fuera posible, por otra parte, que haya un retorno a algo que nunca se ha abandonado del todo). Así pues, el supuesto retorno a la pareja, que se prueba a golpe de sondeos y de estadísticas, puede dar cuenta de un hecho en bruto pero no de su sentido. Vivir con alguien, desear vivir con alguien, puede significar otra cosa que hace treinta años. No es tanto el hecho lo que importa sino su puesta en perspectiva. Hay una polisemia en los signos. El retorno de las cosas no es nunca un retorno a lo idéntico. 
No voy a entonar tampoco un canto de victoria. El porvenir es de lo más incierto. Puedo admitir en mi reflexión la hipótesis según la cual el feminismo de los años setenta fue un meteorito sin futuro, un efecto de superficie. Sin embargo, pienso y trabajo en la hipótesis o postura contraria, según la cual se ha formulado una cuestión radical que concierne la diferencia de sexos y sus respectivas posiciones. Y todo esto bajo el impulso del movimiento feminista pero en el contexto general de los movimientos sociales. Es posible que esta cuestión se resuelva a corto o largo plazo con una reafirmación de la dependencia de las mujeres, pero yo trabajo, también aquí, desde la hipótesis contraria. La cuestión está formulada de forma irreversible: deja oportunidades a las mujeres del año 2000.

¿Desde dónde hablan estas mujeres del año 2000, las jóvenes de la actualidad? ¿En qué mundo han nacido, crecen, van a tener que tomar decisiones? ¿Qué es lo que las aleja relativamente de aquello que es, que fue nuestro, de las que tuvimos veinte años en los años 50,60, 70? ¿En qué lengua hablan, cuyos jeroglíficos tenemos que descifrar nosotras? ¿Qué lengua oyen ellas cuando nosotras hablamos? Estas jóvenes no son solo otras, las otras: son también las otras en nosotras, remontándose a nuestra historia para iluminarla con una nueva luz; con su existencia, refluyen en las décadas pasadas. Y algo de su mundo es nuestro mundo: en la diferencia indiscutible de las generaciones, también somos contemporáneos, viendo amanecer el mismo día, sobre los mismos acontecimientos, desde edades dispares. Independientemente de su interés intrínseco, el feminismo constituye un excelente punto de vista y un excelente revelador de lo que está cambiando en la vida sociocultural occidental. Vemos claramente que un cierto mundo vacila sin percibir exactamente los contornos de aquel que emerge, de forma que éste se define en términos de ciencia y ciencia ficción entremezclados. Lo que nombramos crisis es una crisis, pero no significa sólo una pérdida: también es un crisol.

\section{Transmisión e historia}

Aunque estén emparentadas en ciertos aspectos, la cuestión de la transmisión no puede ser confundida con la cuestión de la historia.

La cuestión de la historia es una cuestión que se plantea al saber: es de naturaleza científica. Se trata, por una parte, de encontrar en el pasado las figuras de mujeres, y por otra, los estratos propios de las mujeres que la historia dominante ha ocultado. Es un trabajo retrospectivo, de excavación y de resurrección de lo que existió y fue indebidamente sepultado. La cuestión de la transmisión, por su parte, se plantea a la práctica ética y política. Se trata de constituir en el presente las condiciones de posibilidad de una filiación simbólica de las mujeres, contra la cual todo el sistema sociocultural opone resistencia. Es un trabajo prospectivo, de insurrección y de elaboración de aquello que aún no existe. 
Por otro lado, la cuestión de la transmisión alimenta la cuestión de la historia. La cuestión de la historia remite a la cuestión de la transmisión.

La cuestión de la transmisión se ha planteado poco o nada, hasta la actualidad, por las mujeres y las feministas, al menos en el sentido en el que la entendemos aquí. Esto es debido, en primer lugar, a la coyuntura. Todas las mujeres que participaron en la emergencia del feminismo de los años 60, 70, han sido adscritas a la misma generación, independientemente de su edad. Precisamente esta fue una de las virtudes del movimiento, reivindicada con orgullo. Feminismo año cero. Todas nacían juntas, en el mismo momento. La elección de la noción de sororidad, que prevaleció durante un tiempo, indica claramente la naturaleza de este fenómeno de igualación que negaba la edad real de las mujeres para otorgarles a todas la edad del feminismo. Sin embargo, a estas motivaciones coyunturales se les añadieron otras: la transmisión entre mujeres ha sido asimilada durante mucho tiempo a la maternidad, reducida a la transmisión de lo ancestral, de lo idéntico, de lo inmutable — de las "recetas"Las mujeres formaban una especie de sociedad inmóvil en el seno de la sociedad de los hombres, abocada a la repetición de los mismos gestos, apenas modificados por la evolución: amar, alumbrar, alimentar, vestir, cuidar. Se proponía a las mujeres el modelo de la conformidad con un género, mucho más que la invitación al ser individuado y a la creación. Además, la voluntad de un "pensamiento colectivo" anónimo, justificado por el miedo al "culto a la personalidad" (heredado paradójicamente de un país en el que imperaba la dictadura de un individuo o de un partido al que relevó la ideología del 68), reforzó dicha tendencia. Durante mucho tiempo, incluso tal vez en la actualidad, las figuras de mujeres innovadoras, en su excepción, no rompieron realmente con este modelo: más bien alimentaban la historia masculina en virtud de la idea implícita según la cual una mujer innovadora es un hombre. Así pues, la maternidad biológica que asegura la transmisión como perpetuación de la especie, de la vida, ha disimulado y obstaculizado la transmisión simbólica que necesita de la posición de singularidades. La cuestión de la generación ha sido reducida a la cuestión de la reproducción.

De hecho, por muy paradójica que parezca esta afirmación, las mujeres han sido hasta la actualidad excluidas de la generación, incluso (y sobre todo) como madres. Se las requería exclusivamente para asegurar las condiciones materiales y morales de la transmisión pero no la actuaban. Ahora bien, la maternidad simbólica implica la posibilidad para una mujer $-\mathrm{y}$ añadiría, con Hannah Arendt, el coraje- de tomar la palabra en su nombre en lugar de ser el canal de un mensaje que no ha elaborado. Necesita acceder, en la interlocución, a lo que los griegos denominaban la paideia, en la medida en la que ésta sustituye la educación que comporta un simple aprendizaje, una adquisición de habilidades, por una iniciativa mediante la cual la mujer se hace initium, comienzo, y provoca en la otra la iniciativa. En efecto, la noción de paideia se distingue del aprendizaje 
en tanto que lo que se aprende no está previamente dado sino que se constituye en el propio trabajo del diálogo.

La paideia no es la transmisión de un modelo (un modelo vivo, una persona) al que habría que ajustarse. Lo que una persona puede provocar es una invitación a ser, a comenzar, a partir de algo o alguien y no con el vacío a la espalda. Este fue, precisamente, el drama de las generaciones anteriores: tener que autoconstituirse sin encontrar en las madres o en las antecesoras este compromiso a ser, tener que arreglárselas a través de lecturas y de algunos encuentros, o incluso tener que oírlo del lado del padre: las madres, las antecesoras, por el contrario, lanzaban una llamada a la prudencia y a la repetición de lo idéntico, en una percepción del tiempo reducido al destino. La relación de paideia favorece ciertas formas de identificación. Sin embargo, esta noción, y esta realidad, debe pensarse con matices, puesto que existen formas de identificación positivas y otras negativas. Es positiva una identificación que, por una parte, otorga a la nueva la posibilidad de comenzar a su vez (identificación a lo que es iniciativa en la antecesora) y que, por otra, deja en su lugar tanto a la antecesora como a la nueva. La mala identificación, la identificación salvaje que el feminismo favoreció a menudo, es una identificación de sustitución por la cual la nueva quiere ocupar el lugar de la antecesora - o a la inversa-, entregándose así a una forma doble de matricidio o de feminicidio. Sólo la primera es generadora de lo simbólico, esto es, de lo abierto: sólo ésta da derecho al lenguaje. La segunda, la identificación por sustitución, es mortífera para una y para la otra, y conocemos los desastres que ha causado. Elabora una relación con una mujer, ciertamente, pero una relación que no deja lugar a la distancia y que no da derecho al lenguaje. Invirtiendo el sentido del viejo eslogan: lo privado es político, la identificación reduce toda manifestación pública a una peripecia privada, reduce el diálogo a la apropiación.

La relación simbólica entre mujeres necesita el reconocimiento de este espacio público en el cual nadie pertenece a nadie, en el que el lenguaje es tomado en serio como modo de presencia y de "presentificación", sin ser reducido a su soporte físico, sin ser confundido con el mero existir. Reconocer a una mujer, de hecho, es reconocer que habla y fiarse de su palabra, saber que su ser es también el ser de su persona y no un substrato detrás de su palabra. Es asumir su presencia como una presencia mediada, siempre diferente y difiriendo de cualquier soporte identitario. Este modo de relacionarnos que hemos comenzado a establecer cuando nos referimos a las obras de mujeres muertas o desconocidas, debemos establecerlo también cuando nos referimos a mujeres vivas, cercanas, cuyo mensaje nos aparece aún demasiado a menudo como una simple emanación de la vida, una expresión entre otras de ésta, y a lo sumo como una modalidad psíquica. Así, adoptamos entonces la actitud de los hombres respecto a ellas, respecto a nosotras, actitud que consiste tradicionalmente en no 
tomarse en serio, con toda su seriedad, lo que dicen las mujeres, reduciendo el sentido que emiten a un síntoma.

\section{Transmisión y afiliación}

La relación de transmisión es una modalidad de la relación de sociabilidad de las mujeres. Después de unos años, de hecho, se ha considerado que había que liberarla de sus metáforas familiares, y particularmente de la de sororidad. La relación entre mujeres debe ser pensada dentro de la categoría de lo simbólico y no de lo biológico, bajo la forma de lo público y no de lo privado; por público interpreto aquí con Hannah Arendt la relación de pluralidad en la que algunos quiénes, algunos alguien, permanecen en su heteronomía, dialogan a través de la acción y de la palabra sin igualarse ni fundirse por ello: es una relación que pasa por la política, por el arte, pero también por la amistad. Lo mismo ocurre cuando la relación se produce entre generaciones, unas generaciones que no son necesariamente de edad sino de anterioridad en el pensamiento o la experiencia; se trata de que las mujeres se generen, en lugar de parirse y sobre todo de infantilizarse mutuamente. Por ello, para designar este proceso prefiero el término de afiliación al de maternidad simbólica, demasiado inscrito en el imaginario familiar. Al contrario, la afiliación debería subvertir la maternidad biológica tal como ésta se ha visto delimitada en la configuración familiar tradicional.

En una comunicación (no publicada a esta fecha) que hice en 1979 en el marco de un coloquio sobre la maternidad, ${ }^{2}$ insistí especialmente en el hecho de que la experiencia del alumbramiento es - contrariamente a lo que se haya podido decir - una experiencia de alteridad ejemplar, mediante la cual del yo sale otro, otra, mediante la cual el yo se experimenta como otro. Esta experiencia perturbadora, que no es la de reproducción de la vida, sino de generación de una vida, ha sido generalmente reducida a una representación de la permanencia de lo mismo que la tradición patriarcal marca con el sello del nombre (del padre). La duración que se asegura a las mujeres mediante la reproducción es la de un tiempo que dejamos venir y que, de madre a hija, toma la apariencia de un retorno cíclico. Es un tiempo que no deja espacio a la palabra: la madre es muda. Las que alumbraban jamás se pronunciaron. No pudieron nunca dar su nombre a su hijo y nunca pudieron nombrarse delante de ellos. No pretendo con esto aseverar que la maternidad ha permanecido hasta ahora encerrada en el mero ciclo vital, pero en todo caso, es así como se la ha tratado de definir. La relación maternofilial debía reducirse a una relación alimenticia, una relación de cuidado (de la vida). Por tanto, la constitución de una temporalidad simbólica entre las

\footnotetext{
${ }^{2}$ Coloquio Filles d'aujourd'hui, femmes de l'an 2000, organizado por la Université de Montréal y la fundación Marie Vincent, celebrado en Montréal en 1985.
} 
mujeres, y de una generación simbólica, me parece el hecho novedoso de nuestra época y la aportación fundamental del feminismo.

La generación simbólica, al abrir un espacio de negociación que pasa por la palabra, al no depender de la de la necesidad sino de la libertad, al permitir a cada una escoger sus modos de parentesco en lugar de tolerarlos, es la única alternativa a los avatares de la maternidad tradicional. Esta alternativa no consiste, vale la pena recalcarlo una vez más, en un rechazo o denigración de la maternidad (que postularía la liberación de ésta mediante "las nuevas técnicas de reproducción"), sino en su reinscripción en el marco más general de las relaciones entre las mujeres. Crear una generación simbólica supone elidir el carácter opresivo y determinante de la generación biológica (o más bien de lo que ha hecho de ella la estructura patriarcal) jugando con los tiempos y los espacios, complicando hasta el infinito los sistemas de parentesco, creando familias de espíritu, favoreciendo acercamientos incongruentes: una "familia" que se reinventa y se remodela en función del deseo, un parentesco de lengua en lugar de sangre o de ley, que se lleva a cabo "viajando a través de las palabras o las imágenes".

Este parentesco simbólico ha comenzado a dibujarse. Las mujeres se han puesto a hablar, escribir, pensar en un número creciente. Sus obras se han multiplicado y publicado hasta llegar a constituir un corpus (¿única versión admisible del cuerpo colectivo?) al cual otras mujeres, las mujeres, pueden referirse a partir de ahora. Sus obras ya no están aisladas. De esta forma, las mujeres jóvenes, cuando piensan, escriben, actúan, pueden referirse a este corpus, alimentarse de él y enriquecerlo. Este corpus no es un objeto aislado de su contexto; no hace sistema, no es la base de un saber ortodoxo que se construye piedra a piedra hasta completar el edificio, sino un espacio de circulación que atraviesa las diferentes disciplinas y las reanima. De esta forma las jóvenes actuales se benefician no sólo de logros legales más favorables, no sólo de modos concretos de relación entre mujeres que han roto su antiguo aislamiento, sino también de una red de signos, presentes en el pensamiento y en la lengua, al que hacen referencia implícita o explícitamente. Una interlocución con los textos y no únicamente con las personas abre un espacio hasta ahora poco transitado a las relaciones entre las mujeres.

No obstante, puesto que el pensamiento, el lenguaje, la escritura de las mujeres apenas está emergiendo, y todavía están ligados a las personas como por un cordón umbilical, la distinción entre relaciones afectivas y relaciones de verdad aún no se ha realizado del todo. Tenemos que comprender primero que las diferencias $u$ oposiciones conceptuales pueden desarrollarse sin que impliquen por ello un ataque feroz a la persona. Debemos aprender que una crítica a nuestro texto no es una amenaza a nuestra existencia. Debemos aprender a despegarnos de lo que producimos y ofrecemos a la aprehensión del otro. Debemos aprender a criticar, esto es, a juzgar, sin que esta crítica parezca 
un ajusticiamiento. Debemos entregarnos a justas simbólicas que no hieran nuestras existencias vulnerables, y llevarlas a cabo de tal forma.

El corpus feminista se reforzará con todas sus aportaciones en la convergencia pero también en la divergencia de ideas e investigaciones. Se trata de constituir y reforzar el espacio de interlocución más que la formación de una doctrina única, necesariamente simplista y esclerotizante. Más fundamental que la constitución de una ciencia feminista, más fundamental que la elaboración de una teoría es la constitución de este espacio sin condición (si queremos que la teoría no degenere en ideología)

La elaboración de un "feminismo cultural" o de una cultura feminista no es, por tanto, la "superestructura" - en sentido marxista- e incluso lo superfluo, de los cambios socioeconómicos: es la condición sine qua non del feminismo, en el sentido en que lo definimos aquí, sin la cual ningún cambio será realmente asumido e incorporado por las mujeres.

Esta cultura feminista no apunta a la fijación de obras "específicas" sobre cuya naturaleza habría que ponerse de acuerdo, sino al desarrollo de la palabra y de la creación de las mujeres, específicas o no, que les permita mantener y desarrollar relaciones constitutivas. La apertura de un espacio hecho de espaciamientos, esto es, de un tiempo que deje de ser repetición.

La cuestión de la transmisión entre generaciones es, pues, una forma de la cuestión más general de la generación de las mujeres unas por las otras, la cuestión de la afiliación. Las jóvenes de hoy están preparadas para acoger una herencia que ya no supone una fatalidad sino algo dado por interpretar.

\section{La afiliación del hijo}

He planteado hasta aquí la cuestión de la filiación, de la afiliación simbólica de mujer a mujer. No obstante, si bien fue el primer objetivo del feminismo, esta cuestión exige a corto o largo plazo un movimiento parecido en la relación con los hombres. Aquí ya no se trata de elaborar algo que no existía sino de acabar con lo que existe. Este proceso es, sin duda, lo único que puede asegurar y manifestar a la vez una renovación de las relaciones de los hombres hacia las mujeres.

Las feministas se han cuestionado a menudo estas relaciones a nivel afectivo, amoroso o sexual. No obstante, estos vínculos no pueden experimentar una verdadera transformación si no se apoyan en un cambio de rumbo de las relaciones simbólicas. Su reto no es una nueva forma de gozar sino una nueva forma de hablar, y de hablarse. Una vez pasado el primer momento de asombro, los hombres entendieron claramente el provecho que podían sacar de la emancipación del placer femenino, y lo integraron rápidamente en sus estrategias, conscientes o inconscientes. 
El cambio de la relación entre sexos depende de que hombres reconozcan haciéndose hijos- que pueden aprender algo de las mujeres, algo del orden de la verdad. Que los hijos lleven un día el nombre de su madre, como las nuevas legislaciones lo prevén, no es sino un síntoma de una transformación más profunda - cuyos signos no son aún del todo perceptibles-, por la cual los hombres meditarían, interpretarían, citarían el pensamiento, la palabra de las mujeres, que merecería su atención, la dedicación de su tiempo.

La culminación del feminismo, que renovaría la práctica de la diferencia, no significa necesariamente que los hombres se pongan al lado de las mujeres en las luchas por el reconocimiento de sus derechos (con el riesgo constante de caer en el paternalismo), sino que significa, ante todo, que algunos hombres, los hombres, reconozcan por primera vez que son deudores de las mujeres, de algunas mujeres, por algo más que la vida o el placer. Y formulo la hipótesis de que el reconocimiento de tal lazo, la constitución de un espacio simbólico compartido con las mujeres, del cual no sólo serían promotores sino beneficiarios, liberaría la figura materna de la temible carga que aún pesa sobre el destino de cada cual. Una mujer que habla da menos miedo que una mujerenigma puesto que abre un espacio de negociación, un espaciamiento, que permite a la vez encuentro y reserva. Reconocer una deuda limitada, enmarcada en una palabra o pensamiento (de mujer) exige tal vez menos que sucumbir a la deuda sin límite hacia la dadora de vida o de placer.

Sin embargo, aquí se plantea una pregunta cuya profundidad no puedo sondear: ¿es capaz un hombre de desear a una mujer que habla? En todo caso, los hombres actuales se enfrentan a esta prueba, y muchos la resuelven mediante una dicotomía entre las mujeres deseadas y las (escasas) mujeres escuchadas, oídas.

Lo que actualmente puede parecer un peso para la figura maternal (el hecho de que las mujeres hayan tomado la palabra) constituye sin duda la única oportunidad de liberación. Aquellos y aquellas que están interesados en la elaboración de nuevas relaciones entre mujeres y hombres deben, en todo caso, aventurarse en esta dirección. La constitución de una relación simbólica, de una filiación simbólica recíproca, es la única salida para las relaciones bloqueadas en el cuerpo a cuerpo.

Dedicarse a escuchar a una mujer, convertirse en el destinatario de su palabra, libera de su influencia global, hace circular el aire allí donde la presencia muda es asfixiante. Se trata, pues, de basarse en lo que dice, más que de permanecer encallado en la inmensidad de su ser.

No obstante, las mujeres que piensan, que hablan, aceptan renunciar a su "misterio", ese misterio que constituía el arma de su seducción. Hablar es manifestarse, aceptándose en su determinación finita y su límite: sustituir el parecer por el aparecer. 
Ponerse a la escucha, afiliarse a las mujeres, no significa invertir la relación de dependencia tradicional sino abrir las posibilidades de un diálogo en el cual la diferencia sexual vuelva a ponerse en juego.

En tal diálogo, lo que es un hombre, lo que es una mujer escapa a su definición. La diferencia de sexos no es un dato - biológico o sociológico- por descifrar y ratificar, es también y sobre todo una cuestión ética-política que toda relación entre una mujer y un hombre, individual o colectiva, renegocia. Es la diferencia la que constituye los diferentes y no a la inversa.

Esta reflexión, determinada al principio por la exigencia de la transmisión en la aparente fractura de las generaciones, se enraíza en la cuestión de la afiliación. Cómo hacer lazo, incluso en el seno de esta fractura, de forma que se pueda escribir no sólo retrospectivamente sino prospectivamente una historia que transforme la historia de la diferencia de los sexos.

\section{REFERENCIAS BIBLIOGRÁFICAS}

Arendt, Hannah (2003): "La crisis de la cultura: su significado político y social" en Entre pasado y futuro. Ocho ejercicios de reflexión política. Barcelona: Península, 303-345.

Arendt, Hannah (2005): La condición humana. Trad. Ramón Gil Novales. Barcelona: Paidós.

Traducción de MAYTE CANTERO SÁNCHEZ 